\title{
Overexpression of miR-155 in clear-cell renal cell carcinoma and its oncogenic effect through targeting FOXO3a
}

\author{
HONG JI $^{1 *}$, DONG TIAN ${ }^{1 *}$, BING ZHANG ${ }^{2}$, YANGYANG ZHANG ${ }^{1}$, DONGLIANG YAN ${ }^{2}$ and SHUHUA WU ${ }^{1}$ \\ Departments of ${ }^{1}$ Pathology and ${ }^{2}$ Urology, Binzhou Medical University Hospital, Binzhou, Shandong 256600, P.R. China
}

Received November 3, 2015; Accepted December 1, 2016

DOI: $10.3892 / \mathrm{etm} .2017 .4263$

\begin{abstract}
MicroRNA-155 (miR-155) is overexpressed in numerous human cancer types and has an oncogenic role. Previous study has revealed that miR-155 serves an important role in the progression of clear-cell renal cell carcinoma (ccRCC); however, the underlying mechanism was not completely clarified. The present study aimed to investigate the biological role of miR-155 in ccRCC and the underlying molecular mechanisms. The expression of miR-155 in $20 \mathrm{ccRCC}$ and adjacent normal kidney tissues was determined by PCR. After downregulation of miR-155 expression by miR-155 inhibitor, cell growth was assessed by MTT and colony formation assays. Apoptosis and cell cycle distribution were analyzed by flow cytometry. Cell invasion and migration was detected by wound healing and Transwell assays. Furthermore, forkhead box O3a (FOXO3a) mRNA and protein expression were detected by PCR and immunoblotting. The expression of FOXO3a in 20 ccRCC tissues was also examined by immunohistochemistry. The expression of miR-155 was upregulated in ccRCC tissues compared to that in adjacent normal tissues. Inhibition of miR-155 significantly suppressed the proliferation, colony formation, migration and invasion, and induced G1 arrest and apoptosis of ccRCC cells in vitro. Moreover, inhibition of miR-155 significantly upregulated FOXO3a expression, and miR-155 expression was inversely correlated with FOXO3a expression in ccRCC tissues. In conclusion, miR-155 may have an important role in the genesis of ccRCC through targeting FOXO3a and may be a potential target for ccRCC therapy.
\end{abstract}

Correspondence to: Dr Bing Zhang, Department of Urology, Binzhou Medical University Hospital, 661 2nd Yellow River Road, Binzhou, Shandong 256600, P.R. China

E-mail: zhangbingbzmc@163.com

*Contributed equally

Key words: renal cell carcinoma, miR-155, FOXO3a, tumorigenesis

\section{Introduction}

The prevalence of renal cell carcinoma (RCC), a renal neoplasm accounting for $\sim 3 \%$ of adult malignancies, has been increasing in the recent years $(1,2)$. Less than $10 \%$ of patients with RCC are reported to have $\geq 5$-year survival rates due to the aggressive nature of the neoplasm, lack of early detection and poor responses to clinical treatments (2). Among the histological subtypes of RCC, clear-cell RCC (ccRCC) is the most common type, accounting for $75-80 \%$ of all RCC cases (3). In the past decades, studies on ccRCC have mainly focused on the genome mutations, expression of protein-coding genes as well as epigenetic changes. However, increasing evidence has indicated that dysregulation of certain microRNAs (miRNAs) is also closely associated with the pathogenesis of $\operatorname{ccRCC}(4,5)$.

miRNAs are a class of non-coding RNAs that exert post-transcriptional control of gene expression by specifically binding to the 3'-untranslation region (3'-UTR) of their target genes (6). miRNAs have been acknowledged to have important roles in a wide range of biological functions, including cellular proliferation, differentiation, development, apoptosis and cellular metabolism (7). Furthermore, miRNAs have been reported to have crucial roles in the pathogenesis and development of cancer. Accumulating evidence revealed aberrant expression of numerous miRNAs in a number of human malignancies $(8,9)$. For instance, miR-155, miR-210, miR-21, miR-17-5p, miR-122 and miR-20 were found to be upregulated in ccRCC, while miR-9, miR-200bc, miR-141, miR-455-5p, miR-363 and miR-429 were reported to be downregulated (10). In addition, apoptosis was induced in cancer cells subjected to overexpression of tumor suppressor miRNAs or silencing of oncogenic miRNAs (11). Taken together, it is reasonable to speculate that miRNAs are novel targets for cancer therapy.

miR-155, localized within a genomic region known as B cell integration cluster, has important roles in immune responses and cancer as well as aberrant proliferation (12-15). Extensive studies revealed that miR-155 has crucial roles in the formation of hematopoietic cells, inflammation and immune reactions as well as in the pathogenesis and development of cancer (16-18). miR-155 was found to be upregulated in ccRCC and may play have an oncogenic effect in RCC (16); however, the exact molecular mechanisms underlying its function in the pathogenesis of ccRCC has remained to be fully elucidated.

Forkhead box O3a (FOXO3a), a target gene of miR-155, is a family member of forkhead transcriptional factor. It 
was reported to be distributed in the nucleus, and to have crucial roles in cellular apoptosis through upregulating B-cell lymphoma 2-interacting mediator of cell death and Fas (19). Furthermore, miR-155 was shown to enhance the expression of the gene growth arrest and DNA-damage-inducible alpha (GADD45A) (20). As FOXO3a is known to regulate GADD45A expression (21), it is reasonable to speculate that miR-155 may be involved in the pathogenesis and progression of ccRCC through targeting FOXO3a. The present study demonstrated that miR-155 is a determinant of cell proliferation and invasion by targeting FOXO3a in ccRCC.

\section{Materials and methods}

Specimens. A total of 20 ccRCC tissue specimens and matched normal kidney tissues were obtained from patients admitted to Binzhou Medical University Hospital (Binzhou, China) from January 2013 to January 2014 immediately after radical nephrectomy. None of these patients received anti-tumor treatment prior to surgery and the diagnosis as ccRCC was histologically confirmed. Tissue samples were immediately frozen in liquid nitrogen after resection and stored at $-80^{\circ} \mathrm{C}$ prior to RNA extraction. Written informed consent was obtained from each patient. The study protocols were approved by the Institutional Review Board of Binzhou Medical University Hospital (Binzhou, China).

Cell culture. The ccRCC cell lines ACHN, 786-0 and CAKI-1 were purchased from the Institute of Biochemistry and Cell Biology (Shanghai, China). The HK-2 human kidney tubular epithelial cell line was purchased from the American Type Culture Collection (Manassas, VA, USA). ACHN and CAKI-1 cells were cultured in Eagle's Minimum Essential Medium supplemented with $10 \%$ fetal bovine serum (FBS) and 786-0 cells were cultured in RPMI-1640 medium supplemented with 10\% FBS (Gibco; Thermo Fisher Scientific, Inc., Waltham, MA, USA). The HK-2 cell line was cultured in KSF medium (Gibco; Thermo Fisher Scientific, Inc.) containing epidermal growth factor (PeproTech, Inc., Rocky Hill, NJ, USA). All cells were cultured at $37^{\circ} \mathrm{C}$ in a humidified incubator with $5 \% \mathrm{CO}_{2}$.

Cell transfection with miR-155 inhibitor. miR-155 inhibitor, single-stranded chemically modified oligonucleotides, was purchased from GenePharma Biological Technology (Shanghai, China). The sequence of the oligonucleotides was 5'-CCCCTATCACGATTAGCATTAA-3'. Cells were transfected with miR-155 inhibitor using Lipofectamine 2000 (Invitrogen; Thermo Fisher Scientific, Inc.) according to the manufacturer's instructions. Following 24, 48 or $72 \mathrm{~h}$ of transfection, cells were harvested and used for further study. Scrambled sequence-transfected cells served as a negative control. The scrambled sequence (GenePharma Biological Technology) was 5'-CATTAATGTCGGACAAC-3'.

RNA extraction and reverse-transcription quantitative polymerase chain reaction ( $R T-q P C R)$. Total RNA was extracted using TRIzol reagent (Invitrogen; Thermo Fisher Scientific, Inc.). Complementary DNA synthesis was performed using $2 \mu \mathrm{g}$ RNA. The RT reaction mixture, which was provided in the PrimeScript 1st Strand cDNA Synthesis kit (cat. no. D6110A; Takara Biotechnology Co., Ltd., Dalian, China) consisted of $1 \mathrm{ml}$ oligo dT primer, $1 \mathrm{ml} \mathrm{dNTP}$ mixture, $2 \mu \mathrm{g}$ total RNA, RNase-free $\mathrm{dH}_{2} \mathrm{O}$. The mixture was incubated at $65^{\circ} \mathrm{C}$ for $5 \mathrm{~min}$, and $5 \mathrm{X}$ PrimeScript Buffer, RNase inhibitor $(0.5 \mu \mathrm{l})$, PrimeScript RTase $(1 \mu \mathrm{l})$ and RNase free $\mathrm{dH}_{2} \mathrm{O}(4.5 \mu \mathrm{l})$ was subsequently added to the upper reaction mixture. The mixture was further incubated at $42^{\circ} \mathrm{C}$ for $30 \mathrm{~min}$, followed by $95^{\circ} \mathrm{C}$ for $5 \mathrm{~min}$. The real-time PCR reaction mixture (SYBR Premix Ex Taq; cat. no. RR041A; Takara Biotechnology Co., Ltd.) was prepared with Takara Ex Taq HS DNA polymerase, dNTP mixture, Mg+, RNase H and SYBR Green I. PCR reactions were performed on an ABI 7500 Real-Time PCR System (Applied Biosystems; Thermo Fisher Scientific, Inc.) under the following conditions: $95^{\circ} \mathrm{C}$ for $10 \mathrm{~min}$, followed by 40 cycles of $95^{\circ} \mathrm{C}$ for $15 \mathrm{sec}$ and $60^{\circ} \mathrm{C}$ for $1 \mathrm{~min}$. All values were normalized to an endogenous U6 control. The sequences of primers used (Sangon Biotech Co., Ltd., Shanghai, China) were as follows: miR-155; forward, 5'-GCGGTTAATGCTAATCGT GAT-3', and reverse, 5'-GTGCAGGGTCCGAGGT-3'; and U6, forward 5'-CTCGCTTCGGCAGCAC-3' and reverse 5'-AAC GCTTCACGAATTTGCGT-3'. The quantification of the PCR results was performed using the $2^{-\Delta \Delta \mathrm{Cq}}$ method as previously described (22).

Cell proliferation assay. ACHN cells $\left(3 \times 10^{4}\right.$ cells/well) were cultured in 96-well plates overnight and then transfected with miR-155 inhibitor. At 24, 48 and $72 \mathrm{~h}$ after transfection, cell growth was examined using the 3-(4,5-dimethylthiazol-2-yl)-2,5-diphenyl-tetrazolium bromide (MTT) assay according to the manufacturer's instructions (Sigma-Aldrich; Merck Millipore, Darmstadt, Germany). The absorbance of samples was recorded at $490 \mathrm{~nm}$ using a microplate spectrophotometer (Model 680; Bio-Rad Laboratories, Inc., Hercules, CA, USA).

Colony formation assay. ACHN cells were transfected with miR-155 inhibitor or control for $48 \mathrm{~h}$ and seeded into 6 -well plates at a density of 1,000 cells/well. After incubation at $37^{\circ} \mathrm{C}$ for 10 days, the cells were fixed and stained with crystal violet. The number of colonies containing $>50$ cells was counted and images were captured using a light microscope (Nikon Corp., Tokyo, Japan) for three independent replicates.

Flow cytometric cell cycle analysis. ACHN cells were cultured in 6-well plates overnight and then transfected with miR-155 inhibitor or control as described above. After $48 \mathrm{~h}$ of incubation, the cell cycle distribution was determined using flow cytometry. In brief, the cells were collected, washed with ice-cold PBS twice and fixed with $70 \%$ cold ethanol at $4^{\circ} \mathrm{C}$ overnight. After incubation in $100 \mu \mathrm{g} / \mathrm{ml}$ RNase A (Sigma-Aldrich; Merck Millipore) at $37^{\circ} \mathrm{C}$ for $30 \mathrm{~min}$, the cells were stained with $50 \mu \mathrm{g} / \mathrm{ml}$ propidium iodide (PI; Sigma-Aldrich; Merck Millipore). Flow cytometric analysis was performed using a FACSCalibur flow cytometer (BD Biosciences, Franklin Lakes, NJ, USA). All experiments were performed at least in triplicate.

Apoptosis assay. ACHN cells were seeded in 6-well plates overnight and then transfected with miR-155 inhibitor or control. After $48 \mathrm{~h}$ of incubation, the cells were harvested 
and washed twice with cold PBS. A total of $1.0 \times 10^{5}$ cells were re-suspended in $100 \mu \mathrm{l}$ binding buffer and mixed with $5 \mu \mathrm{l}$ fluorescein isothiocyanate-labeled Annexin $\mathrm{V}$ and $5 \mu \mathrm{l}$ PI at room temperature for $15 \mathrm{~min}$ in the dark. After addition of $400 \mu \mathrm{l}$ binding buffer, apoptosis was analyzed by flow cytometry.

Wound healing assay. ACHN cells were seeded in 6-well plates overnight and then transfected with miR-155 inhibitor or negative control. After $48 \mathrm{~h}$ of incubation, the cells were scratched with a $200-\mu 1$ pipette tip and then washed three times with PBS to clear cell debris. Fresh medium supplemented with $10 \%$ FBS was added and the cells were allowed to close the wound for $48 \mathrm{~h}$ under normal incubation conditions. Images were captured at the position of the generated wound using a computer-assisted microscope (Nikon Corp.).

Cell invasion assay. Cellular migration assays were performed using a Boyden chamber containing 24-well Transwell plates (Corning Inc., Corning, NY, USA) with 8-mm pore membranes. ACHN cells were transfected with miR-155 inhibitor or negative control. After $48 \mathrm{~h}$ of incubation, $\sim 5 \times 10^{4}$ cells in $200 \mu \mathrm{l}$ culture medium supplemented with 5\% FBS were seeded into the upper chamber. The lower chamber was filled with complete medium (with 10\% FBS) as a chemoattractant. After $12 \mathrm{~h}$ of incubation, the cells on the lower side of the membranes were fixed and stained with crystal violet. Images of the lower surfaces of the membranes were captured at x100 magnification. Five fields of view were randomly selected for the determination of cell migration using NIS-Elements 2.1 software (Nikon Corp.).

Immunohistochemistry. Tissue samples were fixed with formalin and embedded using paraffin. Then $4-\mu \mathrm{m}$ sections were cut and stained using the avidin biotin complex method. The slides were pre-treated by microwaving in $10 \mathrm{mmol} / 1$ citrate buffer ( $\mathrm{pH}$ 6.0) for antigen retrieval. Endogenous peroxidase activity was blocked by incubating with $3 \%$ hydrogen peroxide for $10 \mathrm{~min}$. After blocking non-specific protein binding, tissue sections were incubated with primary antibody to FOXO3a (1:1,000; cat. no. 12829; Cell Signaling Technology, Inc., Danvers, MA, USA) at $4^{\circ} \mathrm{C}$ overnight. After rinsing for $5 \mathrm{~min}$ with PBS three times, sections were treated with horseradish peroxidase (HRP)-conjugated rabbit anti-mouse immunoglobulin G (1:5,000; cat. no. 7074; Cell Signaling Technology, Inc.) for $30 \mathrm{~min}$ at room temperature, followed by incubation with streptavidin biotin complex for $15 \mathrm{~min}$. Subsequent to incubation of the sections with diaminobenzidine for $5 \mathrm{~min}$, they were lightly counterstained with hematoxylin. A four-grade scoring system was used to evaluate the degree of immunostaining under a light microscope (Nikon Corp.): $0,<5 \% ; 1,5-25 \% ; 2$, $25-50 \%$; and $3,>50 \%$ of cells with immunostaining.

Western blot analysis. Cells were lysed with radioimmunoprecipitation buffer and the quantity of the protein was determined using the bicinchoninic acid method (Bicinchoninic Acid Kit for Protein Determination; cat. no. BCA1-1KT; Sigma-Aldrich; Merck Millipore). Protein (80 $\mu \mathrm{g}$ per lane) was subjected to $10 \%$ sodium dodecyl sulfate polyacrylamide gel electrophoresis. Subsequently, the samples were transferred to a Hybond $^{\mathrm{TM}}$ polyvinylidene difluoride membrane (Roche Diagnostics, Indianopolis, IN, USA), which was blocked with $5 \%$ non-fat milk and incubated with mouse anti-human FOXO3a monoclonal antibody (1:1,000; cat. no. 12829; Cell Signaling Technology, Inc.) followed by HRP-conjugated secondary antibody (1:5,000; cat. no. ab191866;, Cambridge, MA, USA). Protein expression was detected using an enhanced chemiluminescence kit (Pierce $^{\mathrm{TM}}$ ECL Western Blotting Substrate; Thermo Fisher Scientific, Inc.). GAPDH (1:5,000; cat. no. 5174; Cell Signalling Technology, Inc.) served as a loading control. The images were captured on X-ray film and quantified using Image J 1.41 software (National Institutes of Health, Bethesda, MD, USA).

Bioinformatics analysis. Potential targets of miR-155 in ccRCC were evaluated using Targetscan software (www.targetscan.org). Via predicted pairing of target region and miR-155, this revealed that FOXO3a was one of the most likely targets.

Statistical analysis. SPSS 16.0 software (SPSS, Inc., Chicago, IL, USA) was used to perform statistical analysis. Each experiment was performed at least in triplicate. All values are expressed as the mean \pm standard deviation. Student's t test or analysis of variance was used for inter-group comparison. Pearson correlation analysis was used to evaluate the correlation between miR-155 expression and FOXO3a expression. $\mathrm{P}<0.05$ was considered to indicate a statistically significant difference.

\section{Results}

miR-155 is upregulated in ccRCC tissues and cell lines. To investigate the potential roles of miR-155 in the pathogenesis of ccRCC, the miR-155 expression in 20 ccRCC samples and paired adjacent normal kidney tissues was determined by RT-qPCR. The results showed that miR-155 expression was significantly upregulated (5.6-fold) in ccRCC compared with adjacent normal kidney tissues $(\mathrm{P}<0.05$; Fig. $1 \mathrm{~A})$. Moreover, this pattern was also observed in cell lines in vitro, as miR-155 was significantly upregulated in the ACHA, CAKI-1 and 786-0 human ccRCC cell lines compared with the HK-2 human kidney tubular epithelial cell $(\mathrm{P}<0.05$; Fig. 1B).

Inhibition of miR-155 reduces the proliferation of ACHN cells. To investigate the role of miR-155 in ccRCC, the influence of miR-155 inhibition on the proliferation of the ACHN ccRCC cell line was examined. First, the cellular proliferation rate was determined by an MTT assay after the cells were transfected with miR-155 inhibitor or negative control for 24, 48 or $72 \mathrm{~h}$. As shown in Fig. 2A, miR-155 inhibition induced a significant decrease on the growth rate of ACHN cells $(\mathrm{P}<0.05)$. In line with this, the colony formation assay revealed that miR-155 inhibition significantly decreased the colony sphere formation after 10 days of culture (Fig. 2B).

Inhibition of miR-155 expression induces apoptosis and cell cycle arrest in ccRCC cells. In the present study, flow cytometric analysis was performed to evaluate the roles of miR-155 in apoptosis of ccRCC cells. As shown in Fig. 3A and B, 

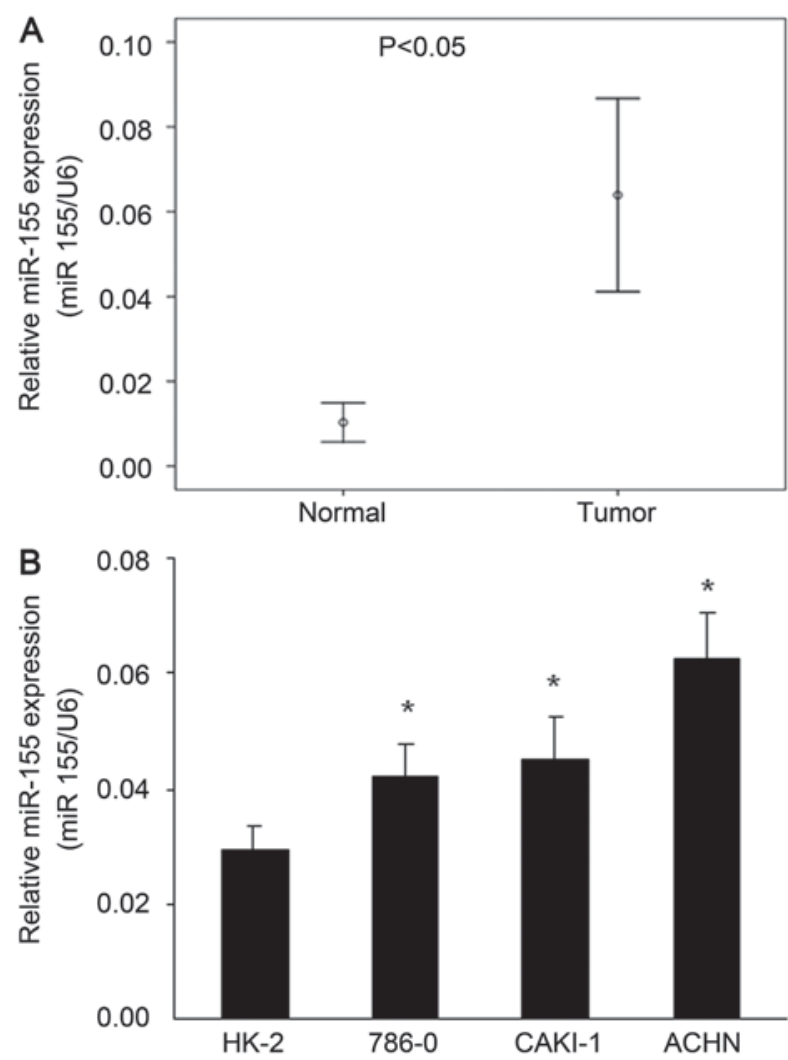

Figure 1. Expression of miR-155 in ccRCC tissues and cell lines. (A) Relative levels of miR-155 in ccRCC tissues as compared to those in matched normal tissues determined using reverse-transcription quantitative polymerase chain reaction analysis. (B) Relative expression of miR-155 in three ccRCC cell lines in comparison with the normal kidney cell line HK-2. ${ }^{*} \mathrm{P}<0.05$ vs. HK-2. ccRCC, clear cell renal cell carcinoma; miR, microRNA.

flow cytometric analysis revealed that the rate of apoptosis was significantly increased in ACHN cells transfected with miR-155 inhibitor $(\mathrm{P}<0.05)$. Taken together, inhibition of miR-155 caused apoptosis in ccRCC cells.

To further analyze the mechanisms by which miR-155 expression affects cell growth, flow cytometric analysis was performed to examine the cell cycle distribution of ccRCC cells after transfection with miR-155 inhibitor. As shown in Fig 3C and D, miR-155 inhibition markedly decrease the percentage of cells in S phase, while the percentage of cells arrested in $\mathrm{G} 1 / \mathrm{G} 0$ phase was obviously increased.Collectively, these results indicated that inhibition of miR-155 resulted in G1/G0 arrest and suppressed ccRCC cell proliferation in vitro.

Inhibition of miR-155 reduces migration and invasion of ccRCC cells. The potential effects of miR-155 on cell migration and invasion were assessed using wound healing and Transwell assays. The wound healing assay demonstrated that inhibition of miR-155 reduced the migratory capacity of the ANCH cells (Fig. 4A and B). The Transwell assay showed that miR-155 inhibition resulted in a reduction of ANCH cell invasion compared with that in the negative control and untreated groups (Fig. 4C and D). Taken together, it is reasonable to conclude that miR-155 may have an important role in the migration and invasion of RCC cells.

FOXO3a is a target gene of miR-155 in ccRCC cells. In order to investigate the underlying mechanism by which miR-155

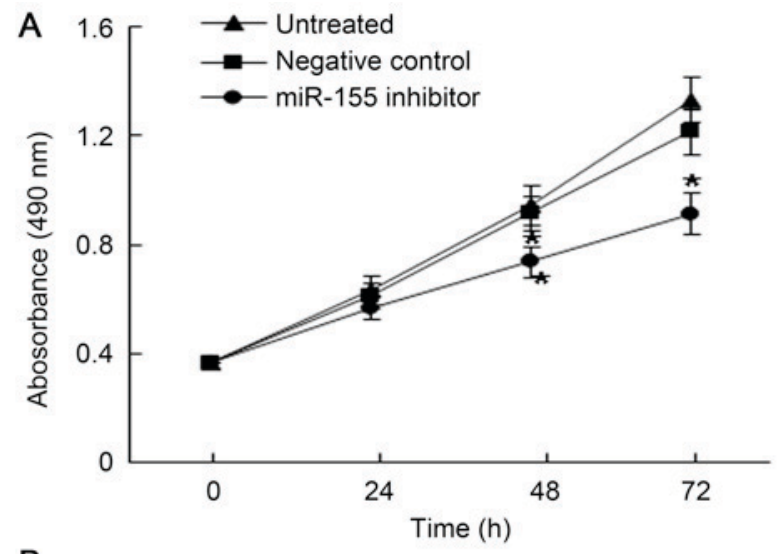

B
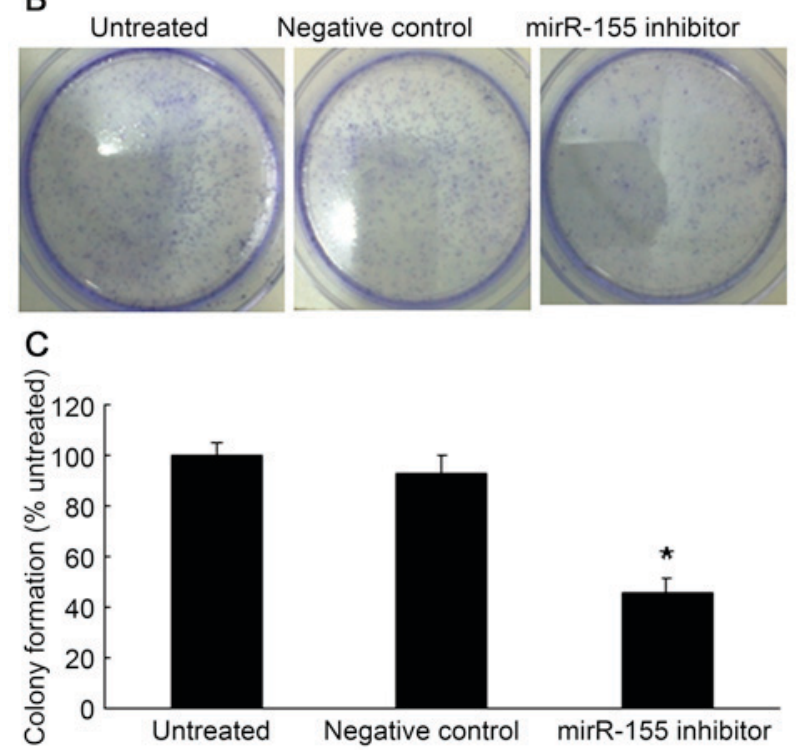

Figure 2. Effects of miR-155 on the proliferation of ACHN cells. (A) An MTT assay was performed to determine the proliferation of cells at 24, 48 and $72 \mathrm{~h}$ after transfection of miR-155 inhibitor. (B) Representative images and (C) quantified results of colony formation of ACHN cells transfected with miR-155 inhibitor. " $\mathrm{P}<0.05$ vs. negative control. miR, microRNA; negative control, mock-transfected group.

may influence the progression of ccRCC, the potential targets of miR-155 were analyzed using Targetscan software. It was demonstrated via the predicted consequential pairing of target region and miRNA that FOXO3a was the target of miR-155 (Fig. 5A). In order to further confirm that miR-155 targeted FOXO3a in ccRCC, the influence of altered miR-155 levels on FOXO3a expression was determined using RT-qPCR and immunoblot analysis. The results indicated FOXO3a protein showed a 2.0-fold increase after miR-155 inhibitor treatment (Fig. 5B).

To further validate the negative regulation of miR-155 on $\mathrm{FOXO} 3 \mathrm{a}$ in vivo, the expression of $\mathrm{FOXO}$ a protein was determined using immunohistochemistry in the same ccRCC tissues in which miR-155 expression was detected. As shown in Fig 5C, FOXO3a was mainly localized in the cellular nucleus. Strong staining signals were observed in the adjacent normal kidney cells, while it was extremely low in the ccRCC cells. Furthermore, the expression of miR-155 was negatively correlated with the expression of FOXO3a $(\mathrm{R}=0.534 ; \mathrm{P}=0.013$; Fig. 5D). 

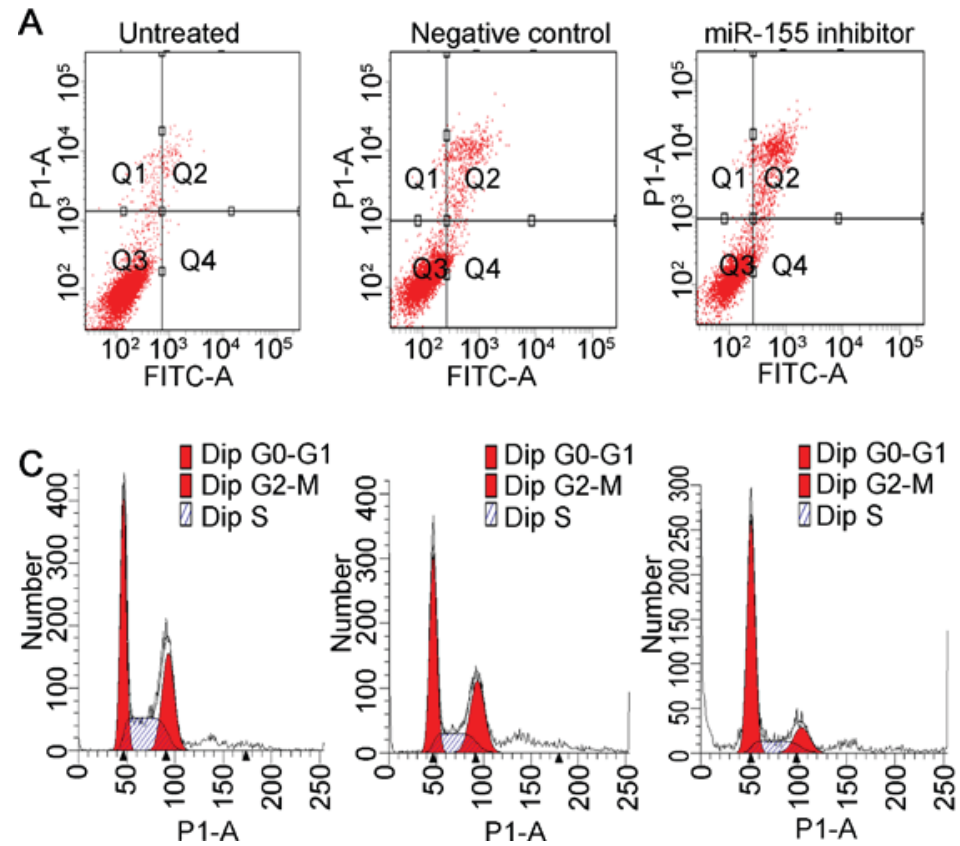
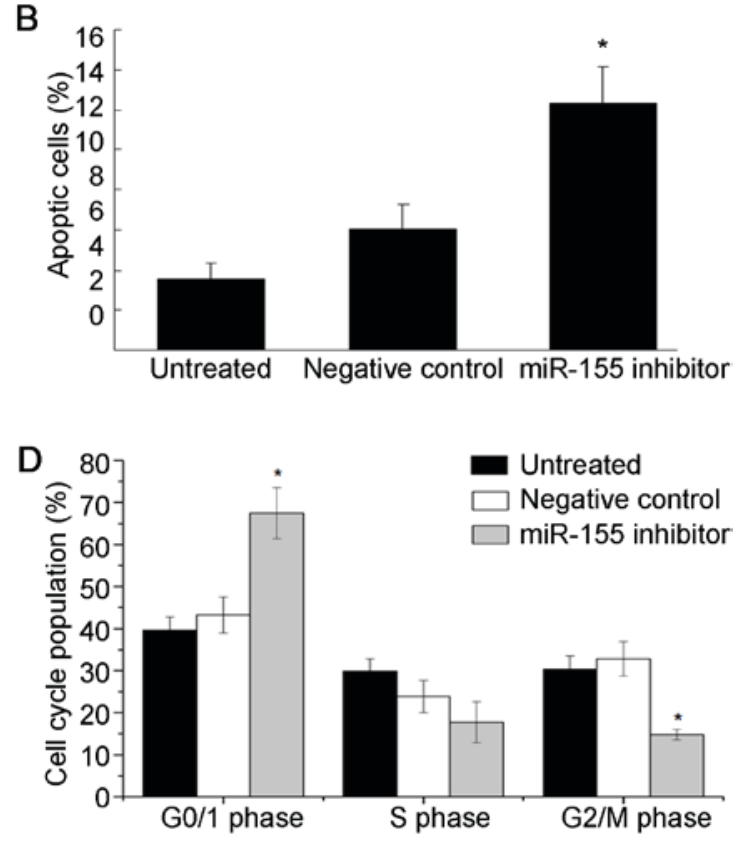

Figure 3. Effects of miR-155 on the apoptosis and cell cycles of ACHN cells. (A and B) Cell apoptosis was detected by Annexin V/PI assay. (C and D) Flow cytometric cell cycle analysis was performed. Data are representative of three independent experiments. "P<0.05 vs. negative control. FITC-A, fluorescein isothiocyanate absorbance; PI, propidium iodide; Q, quadrant; miR, microRNA; negative control, mock-transfected group.

A

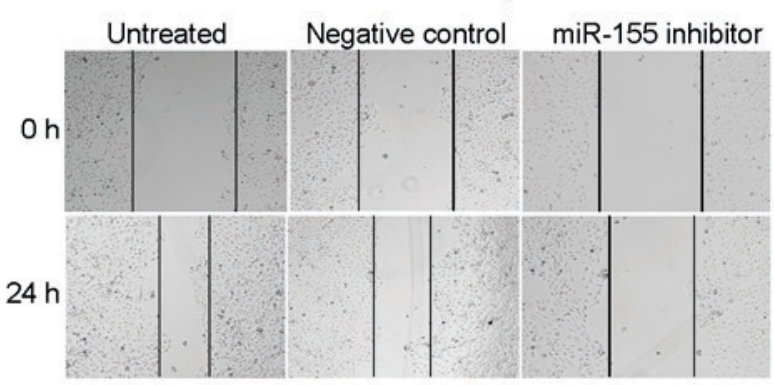

C

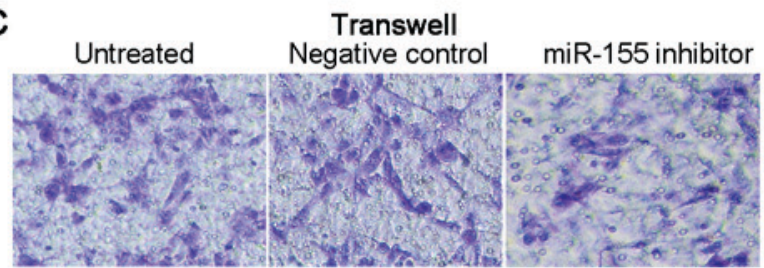

B

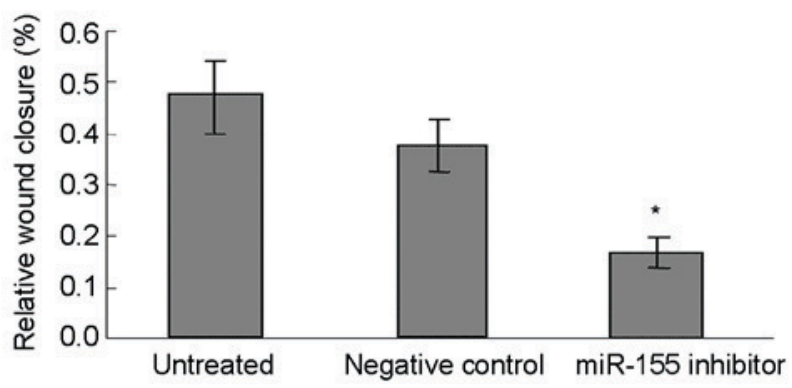

D

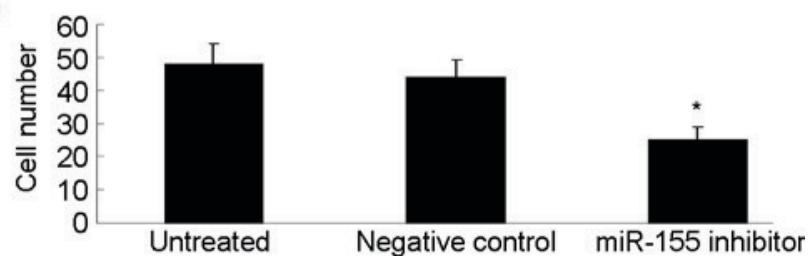

Figure 4. Inhibition of miR-155 suppressed ACHN cell migration and invasion. (A) Representative images (magnification, x20) and (B) quantification of wound healing assay. (C) Representative images of Transwell invasion assay (magnification, x10). (D) Quantification of the number of invading cells. Values are expressed as the mean \pm standard deviation of three independent experiments. miR, microRNA; negative control, mock-transfected group. ${ }^{*} \mathrm{P}<0.05$ vs. negative control.

\section{Discussion}

miRNAs are closely linked with the pathogenesis of tumors and malignant processes $(17,18)$. miR-155 has been shown to be overexpressed in a wide range of malignancies, including carcinomas of breast, lung, pancreas, head and neck (18). However, the molecular mechanisms by which miR-155 exerts its oncogenic role in ccRCC has remained poorly understood. The present study showed that miR-155 expression was significantly upregulated in ccRCC tissues compared with that in corresponding non-tumor tissues. In addition, the levels of miR-155 expression in ccRCC cell lines were significantly higher than that in a normal renal cell line. All of these results are consistent with the notion that miR-155 functions as an oncogenic miRNA in human cancer.

Given that miR-155 is overexpressed in ccRCC and that it acts as an oncomiR, the present study further investigated the functions of miR-155 in ccRCC cells in vitro. The results demonstrated that inhibition of miR-155 significantly decreased ccRCC cell proliferation, colony formation, and induced G1 arrest and apoptosis in vitro. Previous studies have shown that miR-155 enhances malignant tumor phenotypes by promoting 
A

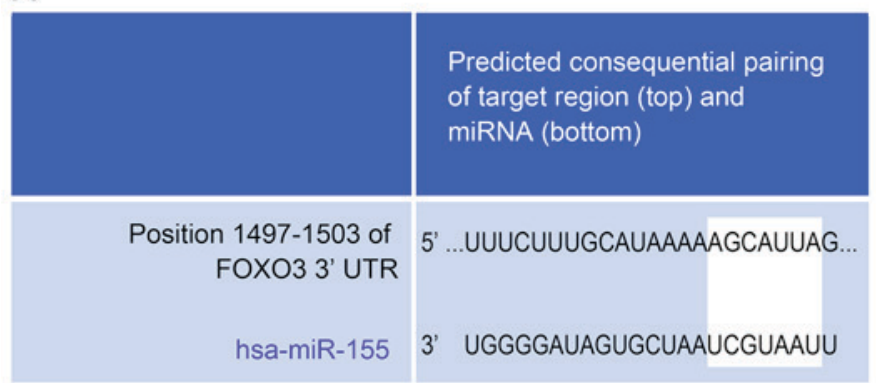

\section{Normal tissues}

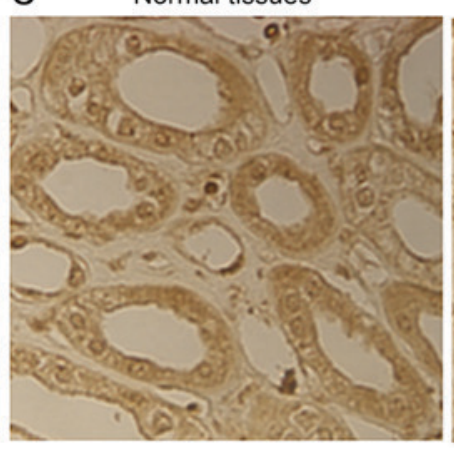

ccRCC tissues

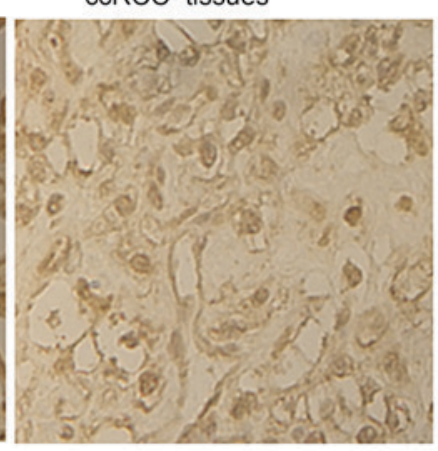

B
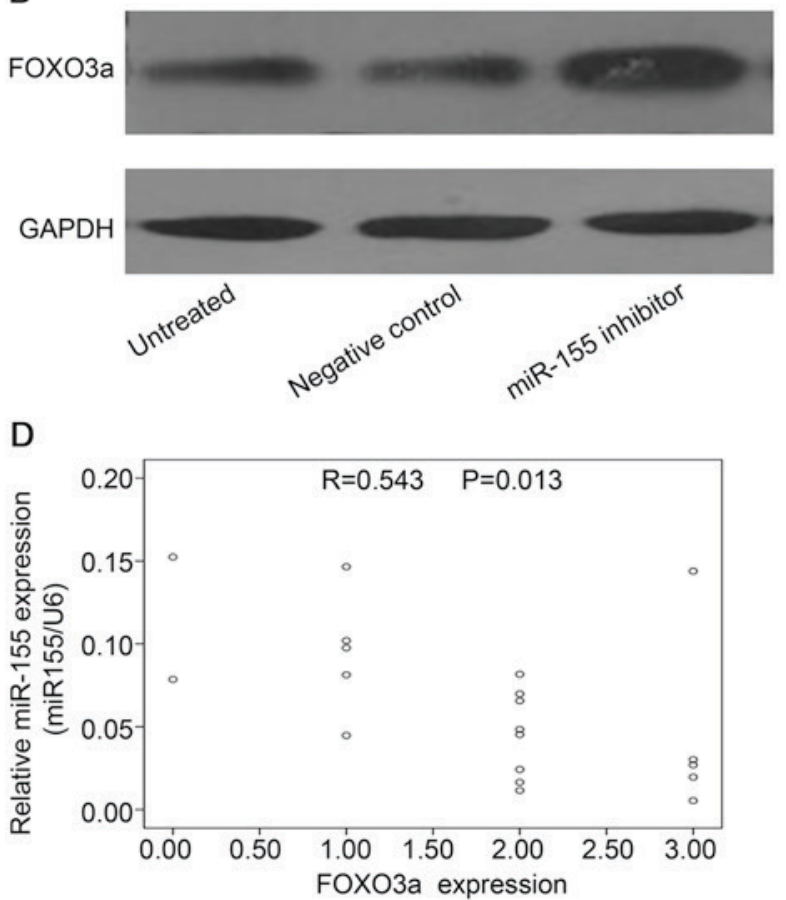

Figure 5. FOXO3a is the direct target gene of miR-155 in ccRCC. (A) Predicted binding sites in the FOX3a 3'-UTR as predicted by Targetscan. (B) Western blot analysis of the expression levels of FOXO3a in ACHN cells after transfection with miR-155 inhibitor. (C) Representative images of immunohistochemical staining for FOXO3a expression in ccRCC and matched normal tissues (magnification, x40). (D) Correlation between miR-155 and FOXO3a in 20 ccRCC tissues. miR, microRNA; negative control, mock-transfected group; ccRCC, clear cell renal cell carcinoma; UTR, untranslated region; FOXO3a, forkhead box O3a; hsa, Homo sapiens.

cell proliferation. For instance, Cai et al (23) showed that overexpression of miR-155 promoted cell proliferation, while inhibition of miR-155 expression induced cell cycle arrest and promoted apoptosis in prostate cancer cells. Lao et al (24) demonstrated that inhibition of miR-155 promoted apoptosis of the cervical cancer cell lines Hela and SiHa and increased the percentage of cells in G1 phase. The present study expanded the current knowledge by highlighting the role of miR-155 in proliferation of ccRCC cells and confirmed the oncogenic role of miR-155 in ccRCC via targeting FOXO3a.

Metastasis is an important step in the progression of ccRCC. Localized and metastatic ccRCC considerably differ in terms of prognosis and therapeutic approach. Indeed, the 5 -year survival rate is $<27.1 \%$ for metastatic ccRCC, but $>70 \%$ for non-metastatic ccRCC (25). Early detection of metastatic ccRCC is difficult due to a lack of reliable molecular markers. The present study further evaluated the role of miR-155 in the metastasis of ccRCC cells. It was revealed that when miR-155 was downregulated, ccRCC cell invasion and migration were inhibited as indicated by wound healing and Transwell assays. These results indicated that miR-155 exerts a promoting effect in the metastasis of ccRCC and may serve as a metastatic marker.

An increasing number of studies have confirmed that miR-155 has crucial roles in the regulation of cancer pathogenesis. For instance, miR-155 was shown to drive telomere fragility in human breast cancer by targeting telomeric repeat factor 1 (26). In addition, it contributed to the proliferation of prostate cancer cells via targeting annexin 7 (23). Furthermore, miR-155 was shown to regulate the proliferation and cell cycle distribution of colorectal cancer cells by targeting E2F transcription factor 2 (27). Each miRNA can have multiple targets, which vary depending on the cell type in which a given miRNA is expressed. To explore the molecular mechanisms underlying the oncogenic effect of miR-155 in ccRCC, FOXO3a was identified as a potential target of miR-155 through a bioinformatics analysis $(28,29)$. FOXO3a is a well studied transcriptional factor that contains a forehead DNA binding domain and has a crucial role in cell growth and apoptosis by transcriptional regulation of a number of genes associated with these processes (30-32). Activation of FOXO3a has a tumor suppressor effect, promoting cell-cycle arrest and apoptosis in RCC cell lines. Recently, a study revealed that downregulation of FOXO3a promotes tumor metastasis and is negatively associated with metastasis-free survival in patients with ccRCC (33). FOXO3a is considered to be a major tumor suppressor in ccRCC. The present study showed that FOXO3a is expressed in adjacent normal kidney tissues and is significantly downregulated in the majority of primary ccRCC tissues. Furthermore, expression of miR-155 was negatively correlated with that of FOXO3a in ccRCC tissues. In addition, downregulation of miR-155 increased FOXO3a expression at the protein level in ACHN cells. These results indicated that miR-155 promotes the progression of ccRCC at least in part by targeting FOXO3a. In order to further comfirm that FOXO3a was directly regulated by miR-155 in ccRCC, a luciferase reporter assay should be performed in future studies (34).

In conclusion, miR-155 was shown to be upregulated in ccRCC and to function as an oncogene in ccRCC by directly 
targeting FOXO3a. Targeting miR-155 may provide an effective therapeutic approach to treat ccRCC.

\section{Acknowledgements}

This work was supported by Binzhou Medical University (Binzhou, China; grant nos. BY2010KYQD01, BY2011KJ018 and BY2011KJ001), Yantai Municipal Scientific Program (grant no. 2014ZH093), and Beinzhou Municipal Scientific Program (grant no. 2014ZC0106).

\section{References}

1. Siegel R, Naishadham D and Jemal A: Cancer statistics, 2013 CA Cancer J Clin 63: 11-30, 2013.

2. Cohen HT and McGovern FJ: Renal-cell carcinoma. N Engl J Med 353: 2477-2490, 2005.

3. Curti BD: Renal cell carcinoma. JAMA 292: 97-100, 2004

4. Ge YZ, Wu R, Xin H, Zhu M, Lu TZ, Liu H, Xu Z, Yu P, Zhao YC, Li MH, et al: A tumor-specific microRNA signature predicts survival in clear cell renal cell carcinoma. J Cancer Res Clin Oncol 141: 1291-1299, 2015.

5. Ishihara T, Seki N, Inoguchi S, Yoshino H, Tatarano S, Yamada Y, Itesako T, Goto Y, Nishikawa R, Nakagawa M and Enokida H: Expression of the tumor suppressive miRNA-23b/27b cluster is a good prognostic marker in clear cell renal cell carcinoma. J Urol 192: 1822-1830, 2014.

6. Cummins JM and Velculescu VE: Implications of micro-RNA profiling for cancer diagnosis. Oncogene 25: 6220-6227, 2006.

7. Alvarez-Garcia I and Miska E: MicroRNA functions in animal development and human disease. Development 132: 4653-4662, 2005.

8. Luo M, Shen D, Wang W and Xian J: Aberrant expression of microRNA-26b and its prognostic potential in human cervical cancer. Int J Clin Exp Pathol 8: 5542-5548, 2015.

9. Ha TY: MicroRNAs in human diseases: From cancer to cardiovascular disease. Immune Netw 11: 135-154, 2011

10. Li M, Wang Y, Song Y, Bu R, Yin B, Fei X, Guo Q and Wu B: MicroRNAs in renal cell carcinoma: A systematic review of clinical implications (Review). Oncol Rep 33: 1571-1578, 2015.

11. Calvo E, Schmidinger M, Heng DY, Grünwald V and Escudier B: Improvement in survival end points of patients with metastatic renal cell carcinoma through sequential targeted therapy. Cancer Treat Rev 50: 109-117, 2016.

12. O'Connell RM, Taganov KD, Boldin MP, Cheng G and Baltimore D: MicroRNA-155 is induced during the macrophage inflammatory response. Proc Natl Acad Sci USA 104: 1604-1609, 2007.

13. Rodriguez A, Vigorito E, Clare S, Warren MV, Couttet P, Soond DR, van Dongen S, Grocock RJ, Das PP, Miska EA, et al: Requirement of bic/microRNA-155 for normal immune function. Science 316: 608-611, 2007.

14. Thai TH, Calado DP, Casola S, Ansel KM, Xiao C, Xue Y, Murphy A, Frendewey D, Valenzuela D, Kutok JL, et al: Regulation of the germinal center response by microRNA-155. Science 316: 604-608, 2007.

15. Tili E, Croce CM and Michaille JJ: miR-155: On the crosstalk between inflammation and cancer. Int Rev Immunol 28: 264-284, 2009.

16. Juan D, Alexe G, Antes T, Liu H, Madabhushi A, Delisi C, Ganesan S, Bhanot G and Liou LS: Identification of a microRNA panel for clear-cell kidney cancer. Urology 75: 835-841, 2010.
17. Chen CZ: MicroRNAs as oncogenes and tumor suppressors. N Engl J Med 353: 1768-1771, 2005.

18. Kumar MS, Lu J, Mercer KL, Golub TR and Jacks T: Impaired microRNA processing enhances cellular transformation and tumorigenesis. Nat Genet 39: 673-677, 2007.

19. Hale JS, Nelson LT, Simmons KB and Fink PJ: Bcl-2-interacting mediator of cell death influences autoantigen-driven deletion and TCR revision. J Immunol 186: 799-806, 2011.

20. Bouamar H, Jiang D, Wang L, Lin AP, Ortega M and Aguiar RC: MicroRNA 155 control of p53 activity is context dependent and mediated by Aicda and Socs1. Mol Cell Biol 35: 1329-1340, 2015.

21. Amente S, Zhang J, Lavadera ML, Lania L, Avvedimento EV and Majello B: Myc and PI3K/AKT signaling cooperatively repress FOXO3a-dependent PUMA and GADD45a gene expression. Nucleic Acids Res 39: 9498-9507, 2011.

22. Livak KJ and Schmittgen TD: Analysis of relative gene expression data using real-time quantitative PCR and the 2(-Delta Delta C(T)) Method. Methods 25: 402-408, 2001.

23. Cai ZK, Chen Q, Chen YB, Gu M, Zheng DC, Zhou J and Wang Z: microRNA-155 promotes the proliferation of prostate cancer cells by targeting annexin 7. Mol Med Rep 11: 533-538, 2015.

24. Lao G, Liu P, Wu Q, Zhang W, Liu Y, Yang L and Ma C: Mir-155 promotes cervical cancer cell proliferation through suppression of its target gene LKB1. Tumour Biol 35: 11933-11938, 2014.

25. Novara G, Ficarra V, Antonelli A, Artibani W, Bertini R, Carini M, Cosciani Cunico S, Imbimbo C, Longo N, Martignoni G, et al: Validation of the 2009 TNM version in a large multi-institutional cohort of patients treated for renal cell carcinoma: Are further improvements needed? Eur Urol 58: 588-595, 2010.

26. Dinami R, Ercolani C, Petti E, Piazza S, Ciani Y, Sestito R, Sacconi A, Biagioni F, le Sage C, Agami R, et al: miR-155 drives telomere fragility in human breast cancer by targeting TRF1. Cancer Res 74: 4145-4156, 2014.

27. Li T, Yang J, Lv X, Liu K, Gao C, Xing Y and Xi T: miR-155 regulates the proliferation and cell cycle of colorectal carcinoma cells by targeting E2F2. Biotechnol Lett 36: 1743-1752, 2014.

28. Kong W, He L, Coppola M, Guo J, Esposito NN, Coppola D and Cheng JQ: MicroRNA-155 regulates cell survival, growth and chemosensitivity by targeting FOXO3a in breast cancer. J Biol Chem 285: 17869-12879, 2010

29. Spinetti G, Cordella D, Fortunato O, Sangalli E, Losa S, Gotti A, Carnelli F, Rosa F, Riboldi S, Sessa F, et al: Global remodeling of the vascular stem cell niche in bone marrow of diabetic patients: Implication of the microRNA-155/FOXO3a signaling pathway. Circ Res 112: 510-522, 2013.

30. Anderson MJ, Viars CS, Czekay S, Cavenee WK and Arden KC: Cloning and characterization of three human forkhead genes that comprise an FKHR-like gene subfamily. Genomics 47: 187-199, 1998.

31. Tran H, Brunet A, Grenier JM, Datta SR, Fornace AJ Jr, DiStefano PS, Chiang LW and Greenberg ME: DNA repair pathway stimulated by the forkhead transcription factor FOXO3a through the Gadd45 protein. Science 296: 530-534, 2002.

32. Sunters A, Fernández de Mattos S, Stahl M, Brosens JJ, Zoumpoulidou G, Saunders CA, Coffer PJ, Medema RH, Coombes RC and Lam EW: FoxO3a transcriptional regulation of Bim controls apoptosis in paclitaxel-treated breast cancer cell lines. J Biol Chem 278: 49795-49805, 2003.

33. Ni D, Ma X, Li HZ, Gao Y, Li XT, Zhang Y, Ai Q, Zhang P, Song EL, Huang QB, et al: Downregulation of FOXO3a promotes tumor metastasis and is associated with metastasis-free survival of patients with clear cell renal cell carcinoma. Clin Cancer Res 20: 1779-1790, 2014.

34. Ling $\mathrm{N}, \mathrm{Gu}$ J, Lei Z, Li M, Zhao J, Zhang HT and Li X: microRNA-155 regulates cell proliferation and invasion by targeting FOXO3a in glioma. Oncol Rep 30: 2111-2118, 2013. 